\title{
Connecting Culturally and Spiritually to Healthy Eating: A Community Assessment with Native Hawaiians
}

http://digitalscholarship.unlv.edu/apin/

\author{
Mary Frances Oneha ${ }^{\mathrm{a}}$, Joan Dodgson ${ }^{\mathrm{b}}$, Mabel Ho`oipo DeCambra ${ }^{\mathrm{c}}$, Carol Titcomb ${ }^{\mathrm{a}}$, \\ Rachelle Enos ${ }^{\mathrm{b}}$, \& Sandie Morimoto-Ching ${ }^{\mathrm{b}}$
}

\begin{abstract}
Many of the chronic illnesses disproportionately experienced by Native Hawaiians are directly related to poor diets and long-standing obesity beginning in childhood. We report on the findings of in-depth key informant interviews $(N=14)$ that took place in two Native Hawaiian communities as part of a larger, community-based participatory research study that included a community assessment through individual interviews and focused group discussions, and a pilot intervention targeting pregnant women, their infants, and families. Four categories emerged from the qualitative analysis of interview transcripts that described an understanding of "healthy eating": family roles and responsibilities, aspects of community and physical environment, deeper spiritual meaning of food, and ways of operationalizing personal eating choices. The findings revealed previously undocumented intergenerational influences on healthy eating patterns and informed the design of the next study phases and are of significance in targeting nutritional interventions for Native Hawaiians.
\end{abstract}

Keywords: community-based participatory research, chronic disease, diet, health status disparities, Native Hawaiians

Native Hawaiians present with significant health disparities, higher than average mortality and morbidity due to all major chronic diseases, and an expected life span shorter than most in Hawaii (Hawai i State Department of Health, 2011; Look, Trask-Batti, Agres, Mau, \& Kaholokula, 2013; Pobutsky, Balabis, Nguyen, \& Tottori, 2010). A concerted effort to reduce these disparities has been undertaken at the state and local levels by program planners, policy-makers, public health practitioners, funders, and health care providers. As with health disparities in other marginalized populations, in-roads have been made in improving (a) the accuracy of data collection; (b) health care provider's awareness and knowledge; (c) providing a seat at the table for members of these disenfranchised communities; (d) public awareness; and (e) the development of small, localized, and frequently non-sustainable health promotion and disease prevention programs targeting specific disparities (e.g., obesity, diabetes, cancer). However, to truly change the trajectory and impact of chronic illnesses within a marginalized population, such as Native Hawaiians, innovative culturally relevant and community generated approaches are required.

Many of the chronic illnesses experienced by Native Hawaiians are directly related to poor diets (Novotny et al., 2012) and obesity. Forty-one percent of Native Hawaiians are obese and $34 \%$ are overweight (Hawai i State Department of Health, 2013) resulting in concurrent high rates of diseases related to obesity. For example, the prevalence of diabetes among Native Hawaiians is $12.8 \%$, higher than the prevalence in the State at $9.7 \%$ (Hawai i State Department of Health, Behavioral Risk Factor Surveillance System, 2016b). Similarly, the prevalence of heart disease among Native Hawaiians $(4.2 \%)$ is higher than any other racial group and higher

\footnotetext{
${ }^{a}$ Waimānalo Health Center, USA

${ }^{b}$ Waianae Coast Comprehensive Health Center, USA

${ }^{c}$ Wai 'anae Coast Community Mental Health Center, Inc., USA
}

Corresponding Author:

Mary Frances Oneha, APRN, PhD

Chief Executive Officer

Waimanalo Health Center

Email: MOneha@waimanalohealth.org 
than the State $3.4 \%$; Hawai i State Department of Health, Behavioral Risk Factor Surveillance System, 2016a), as is high blood pressure at $29.7 \%$ compared to the State at $28.5 \%$ (Hawai i State Department of Health, Behavioral Risk Factor Surveillance System, 2015).

Longstanding obesity beginning in childhood is a particular threat to health. Longitudinal studies provide evidence that obesigenic behaviors in childhood and adolescence track into adulthood (Lipsky et al., 2015), and overweight children are more likely to become obese adults (Serdula et al., 1993). The finding that Native Hawaiian children have the highest prevalence of obesity in Hawai'i signifies ever widening disparities in health, with significantly higher medical costs, a poor quality of life, and a shorter life span (Pobutsky et al., 2010).

Better outcomes for newborns are achieved with earlier interventions. The prenatal period is the appropriate time to intervene with expectant mothers on making healthy food choices for their newborn. That stage in the life cycle of a family in anticipation of the birth of a new member is an ideal time for health interventions. Families are primed to receive health messages and motivated to effect lifestyle changes. While evidence abounds as to the role of parents in shaping the eating behaviors of children, little is known about contextual influences of feeding within the Native Hawaiian family system ('ohana). Effective interventions must address the modifiable risk factors (poor diet, lack of physical activity, etc.) and align "with the social, demographic, environmental, economic, and geographic attributes of the neighborhoods where people live and work" (Yoon, Bastian, Anderson, Collins, \& Jaffe, 2014, p. 372).

Caring for the land (aloha 'äina and malama 'àna) is a significant value for Native Hawaiians. Food for many indigenous peoples is relational, there is an attachment to food that is more than a product or commodity. The origin of Native Hawaiians is derived from the kalo (taro) plant. The cosmology of the Hawaiian people describes the union of Papa (Earth Mother) and Wākea (Sky Father) which gave rise to two sons. The first, unformed, was buried in the earth giving rise to the first kalo (taro) plant; while the second became the ancestor of the Hawaiian people (Kame eleihiwa, 1992). The name of the firstborn is literally "trembling leaf on a long stalk," which describes the taro leaf but is also an apt description of the human placenta. Some interpret this to mean that kalo was the figurative placenta for the first human, providing sustenance for all mankind from time immemorial (Aluli-Meyer, 2015).

Historically and currently, Native Hawaiians are collectivistic, 'ohana, and community focused. This characteristic is reflected in the greater average household size in the participating communities of
Wai'anae (4.1) and Waimānalo (4.3) as compared to State (3.0) and National (2.6) averages (U.S. Census Bureau, 2014). The household size also reflects that more than half are individuals under the age of 18 years in Waianae $(54.2 \%)$ and Waimānalo (52.5\%; U.S. Census Bureau, 2010). Therefore, any research aiming to affect health disparities in Native Hawaiian communities through behavioral change must take a family oriented approach. The purpose of the study was to pilot test a culturally relevant approach that would change the trajectory of chronic illness with a Native Hawaiian community through focusing on the perinatal period and starting a child out with the best nutrition possible.

\section{Methods}

\section{Design}

An intergenerational approach (Miller, 2007; Thompson, 2013; Thompson-Reid, 2009) combined with community-based participatory research (CBPR) methods was used to engage a broad spectrum of the Native Hawaiian community in two distinct geographic areas on the island of O'ahu in the State of Hawai $i$. The strength of intergenerational social and behavioral components that perpetuate both healthy and unhealthy lifestyles within this community cannot be overstated. This was accomplished through a structured community assessment consisting of two phases: 1) key informant interviews and 2) group sessions in Native Hawaiian communities. The findings from these assessments informed the design of a pilot intervention targeting pregnant women, their infants and family, and prompting them to examine the chronic illness trajectories and dietary patterns of their families over the past three generations. This article focuses on the first phase of the community assessment, key informants' understanding of healthy nutrition.

Qualitative methods allow participants to reflect upon what they do and why (Bisogni, Jastran, Seligson, \& Thompson, 2012). These methods can uncover heretofore unknown factors through unprecedented responses to semi-structured interview questions. The in-depth interview format affords a more nuanced and detailed picture of a complex and contextual behavior than the more traditional quantitative food inventory and structured survey. This study was approved by the Waianae Coast Comprehensive Health Center Institutional Review Board.

\section{Context}

This research study was conducted in the communities of Wai anae and Waimānalo, located on the west and east side of the island of O'ahu, respectively. These communities comprise $59 \%$ and $29 \%$ of 
Native Hawaiians, respectively, representing two of the top three communities with Native Hawaiians on the island of O'ahu (Hawai i State Department of Health, 2012). The Wai anae community is home to the largest population of Hawaiian Homelands residents in the state with three homestead sites (lands set aside for Native Hawaiians by Congress in the Hawaiian Homes Commission Act of 1920). The total population of Wai anae is 48,519 (U.S. Census Bureau, 2010), with a median age of $30.5,24.3 \%$ of individuals are below the poverty level, $15.5 \%$ are unemployed, and $7.5 \%$ are uninsured (U.S. Census Bureau, 2013). Wai anae has the highest infant mortality rate for the island of O'ahu and the second highest in the State (Hawai i State Department of Health, 2012). Researchers (Hirai, Hayes, Taualii, Singh, Fuddy, 2013) have attributed high Native Hawaiian infant mortality to pre-term related causes, sudden unexpected infant death, and injury. Maternal education, maternal age, and smoking were also contributors to infant mortality.

Nearly 2,000 acres of land in Waimānalo are under the management of the Department of Hawaiian Homelands. Waimānalo is a clearly defined geographic community with a population of 10,034 (U.S. Census Bureau, 2010). The population demographics reflects a median age of 34 years, $14 \%$ of individuals are below the poverty level, $10 \%$ are unemployed, and $7.3 \%$ are uninsured (U.S. Census Bureau, 2013). Both communities consistently have unemployment rates higher than the State average (7.1\%), individuals below the poverty level (11.2\%), and uninsured (7.1\%). The communities also have households with more than $50 \%$ comprised of related children under the age of 18 (Wai anae $=52.4 \%$; Waimānalo $=56.7 \%$; State $=$ $36.7 \%$; U.S. Census Bureau, 2013). In addition to the socioeconomic challenges, chronic diseases are overwhelmingly represented within the Native Hawaiian population. Specifically, Native Hawaiians have higher rates (12.5\%) of diabetes than other Asian and Pacific Islander groups (e.g., 6.3\% of Japanese and 9.9\% of Filipino) and are more likely to die at earlier ages from the disease and its complications than Caucasians. Native Hawaiians also have the highest diabetes mortality rate of any ethnic group in the State. In a survey completed through the Hawai i Behavioral Risk Factor Surveillance System (Nguyen \& Salvail, 2013), the percent of individuals told by a doctor or health professional that they have diabetes was $7 \%$ in Kailua/Waimānalo and 14.7\% in Nānākuli/Wai anae the highest in the state as identified in the Hawai ${ }^{\prime}$ Behavioral Risk Factor Surveillance System.

\section{Conceptual Framework}

CBPR is both a method and a philosophical approach to working within communities. It is congruent with Native Hawaiian values and approaches, which also formed the conceptual underpinnings of this study. The underlying assumption is that disruptions in cultural traditions through socio-economics and colonization have significantly contributed to the health disparities now experienced by Native Hawaiians. Indigenous cultures, particularly those that have been colonized (e.g., Native Hawaiian), are generations away from living according to cultural traditions and operate within another cultural milieu. Therefore, researching current understandings within indigenous communities is not truly researching traditional culture but a unique hybrid that has emerged over decades (Wilson, 2001). It is our perspective that developing culturally relevant health promotion and support programs that reflect a decolonizing approach (Oneha, 2001), facilitates the reconnection of Native Hawaiian people with their cultural values, practices, and traditions, which improves their health on many levels (e.g., spiritually, physically and psychologically). This study was designed to provide these reconnection opportunities throughout each phase of the study.

\section{Community-Based Participatory Research and the Research Team}

The central question in CBPR is what constitutes participation and who is participating (Wallerstein \& Duran, 2008). In operationalizing the CBPR principles of community engagement and mutual participation, the research team stemmed completely from within the community. The co-creators were two community health centers and community members. The project was implemented by researchers and consultants who were embedded within the Native Hawaiian community, and who understood the health and socio-cultural contexts of this population. The principal investigators, one from each community health center and a third community member, have extensive experience working with Native Hawaiian communities and in conducting CBPR. The majority of the research team, including two of the three principal investigators, are Native Hawaiians, who reside or work in communities served by the participating community health centers.

Waianae Coast Comprehensive Health Center had an established Community Advisory Group (CAG) of six individuals representing different sectors of their community; Waimānalo Health Center identified three additional members from their community bringing the size of the study CAG to nine. The role of 
the CAG evolved over the course of the project, as the research team and CAG co-created the community assessment and pilot intervention.

\section{Participants}

Key informants were recruited by the research team from the community health center and by the CAG from the community, for a semi-structured qualitative interview. Participants were included if they were Native Hawaiian, 18 years and older, living in the communities of Waimānalo or Wai anae, and interested in speaking about healthy nutrition. An equal number of participants from each of the two communities were recruited. The CAG members were invited to participate in the key informant interviews and/or to recommend other community members who could provide valuable insights concerning our focus area. The additional key informants were approached, after CAG member's secured approval for the researcher to do so. This strategic selection process, augmented by snowball sampling, is a culturally appropriate means of gathering data to further understand and generate ideas about our topic.

Table 1. Demographics of Participants

\begin{tabular}{lrr}
\hline Variable & $n$ & $\%$ \\
\hline Age (Years) & 6 & 42.86 \\
$35-55$ & 7 & 50.00 \\
$56-70$ & 1 & 7.14 \\
$>70$ & & \\
Years in Community & 2 & 14.29 \\
$0-15$ & 4 & 28.57 \\
$16-30$ & 5 & 35.71 \\
$31-50$ & 3 & 21.43 \\
$>$ 50 & & \\
Marital Status & 2 & 14.30 \\
Single & 8 & 57.10 \\
Married & 3 & 21.40 \\
Divorced & 1 & 7.10 \\
Living w/ Partner & & \\
Education Level & 4 & 28.60 \\
High School & 3 & 21.40 \\
Some College & 7 & 50.00 \\
More than 4 Years & & \\
With Children & 2 & 14.30 \\
No & 12 & 85.70 \\
Yes & & 78.60 \\
Employed & 11 & \\
Yes & & \\
Retired & & \\
Work at Home & & \\
\hline
\end{tabular}

The 14 individuals who participated in the interviews were female (Table 1). While men were not excluded from the study, the participants, who were members of the CAG or recommendations from the $\mathrm{CAG}$, who consented, were female. The majority were 56-70 years of age $(M=50.6$ in Wai' anae and 56.6 in Waimānalo), and have resided in their respective communities for 31-50 years $(M=34.0$ years in Wai anae and 37.6 years in Waimānalo).

All interviews were conducted, in the participant's community, at a place of their choosing, which was usually at their home or at a community organization. The interview sessions ranged from 30-50 min. Ethical considerations of confidentiality and security of records were reviewed with the participant. All participants signed an informed consent form, approved by the institutional review board, which included a description of the study and their rights and responsibilities. Participants were informed that their participation in this study was strictly voluntary, and they could choose not to participate or withdraw from the study at any time. A gift card valued at $\$ 20$ was provided to each participant after the interview. Interviews were audiotaped and transcribed. Participants were identified by alphanumeric codes and transcripts were stripped of any identifiable information. All data were stored in a locked file cabinet accessible only to the project research team.

\section{Table 2. Interview Questions}

Tell me the story of the last time you felt you ate well? When your body and soul was satisfied? Does this happen often? Why or why not?

What does a meal look like? How do you plan a meal? (For yourself or your family?)

What is your family's role or involvement in meal planning? Is this a family's responsibility?

Is the meal planning different for adults, pregnant women, and children or infants?

Do you think about nutrition or healthy eating consciously or is this something innate?

What, about this community or this place, helps you to eat well? What, about this community or place, challenges or makes it hard for you to eat well?

Tell me about 2 things that created the most change in your life? What motivated you to move in this direction or think differently? 


\section{Interview}

Interview questions were generated by the research team and community members, to provide structure for direction, without leading the discussion (Table 2). Other questions were asked to prompt more detail, clarification, or have the participant provide an example. Participants were informed that the researchers were interested in hearing their thoughts about the current nutrition issues they see for Native Hawaiian mothers and their infants. "Nutrition issues" referred to what mothers eat, what their infants eat, how they choose what to eat for themselves and for their infant, how they know they ate well, how they plan a meal, how they get access to what they eat, or where they go or who they ask to know what is "healthy eating." Participants were given paper and a pencil to write notes that they felt would be meaningful to them. Towards the end of the interview, they were asked to identify two to three factors that struck them in the interview and that they would want to take home or would be useful to them.

\section{Analysis}

Content analysis (Elo et al., 2014; Krippendorff, 2013) of the transcribed interviews occurred as an iterative process with the entire research team. Codes were identified from the transcript content and the associated quotes were organized under each identified code. Each code was defined to ensure a common understanding within the research team. Transcripts were reviewed and coded independently by researchers, after which the team met to compare findings, group codes conceptually into categories that identified themes across interviews. Participants, who were members of the CAG, were also presented with the categories to see if they captured the essence of their interview.

Table 3. Categories from Data Analysis

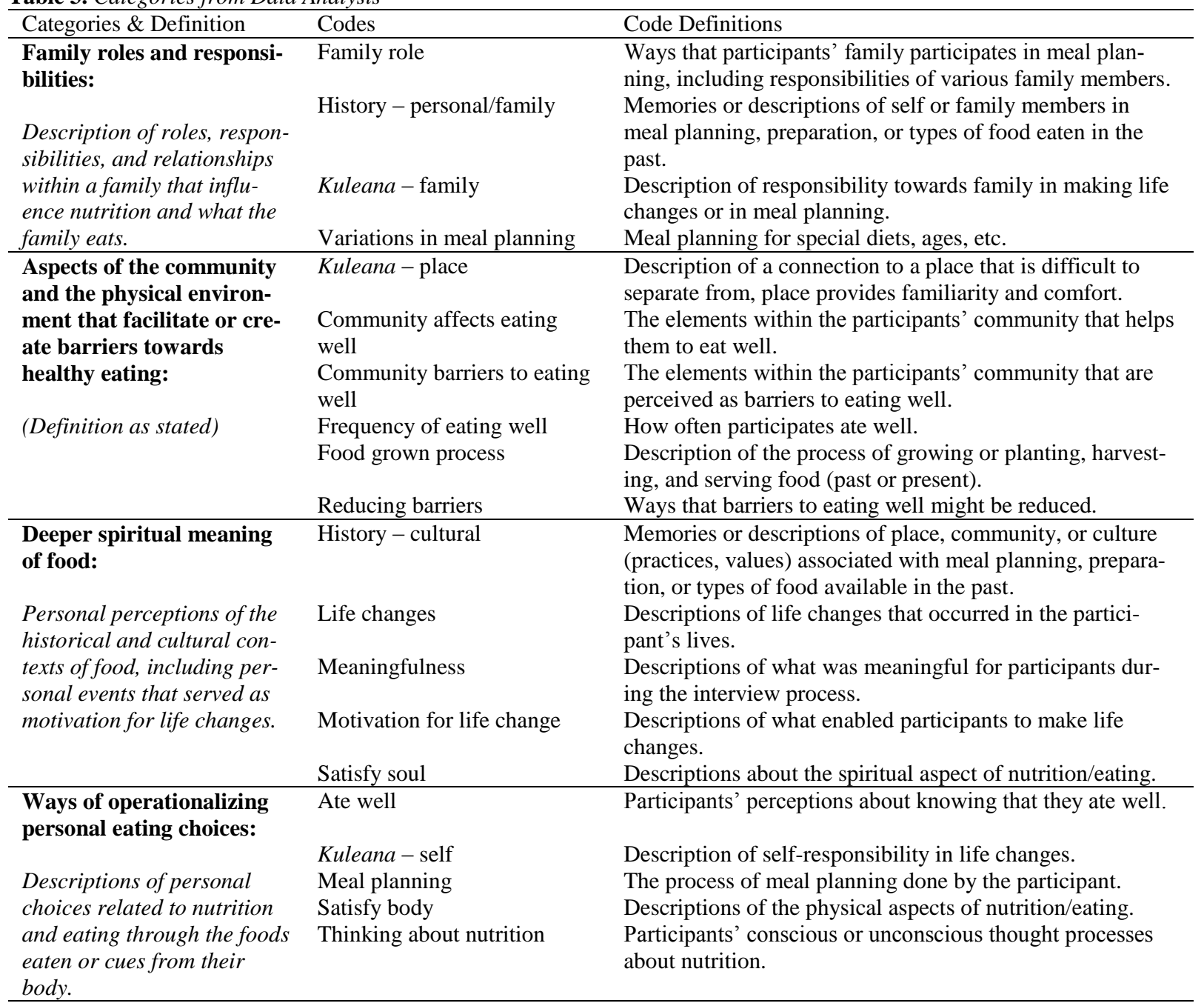




\section{Results}

Four categories emerged from this process (Table 3). The categories described the key informants' understanding of "healthy nutrition" or "healthy eating" for their family, including expectant mothers and their infants.

\section{Family Roles and Responsibilities}

The first category, family roles and responsibilities, described roles and responsibilities within a family that have influenced nutrition and what the family ate. One participant identified the responsibility (kuleana) of family members in gathering healthy food for an expectant mother:

All the family had kuleana, one part of the family would go and get the limu [seaweed] for her and gathered all these things to make this mother healthy. I didn't realize how blessed I was to have witnessed this. I saw how my aunties, uncles, everybody was all part of this.

Another participant shared how meal planning would change if a grandchild was on the way, "I don't have grandchildren, but if there was one coming and they were living in my home, it would change a lot, more fruits and vegetables, more soups, chicken, not so much pork." The role of the person who does the cooking was described, and although suggestions were made for healthy alternatives, this participant conceded to the person who was cooking:

I don't do the cooking much anymore, my husband does. We both have different definitions of what is healthy. I try to say things; we need to add more greens to our meal or fruits and maybe less frying. But because he is doing the cooking and I am not, I don't want to grumble.

Similarly, a participant identified the job of cooking with a specific person in her household, "I go home, dinner is cooked. My mother-in-law lives with us and that's her job." For other participants, purchasing groceries and preparing the food are separate responsibilities, "I kind of purchase the groceries and then it's prepared by other people." Living in a multifamily household resulted in specific cooking schedules and conscious meal planning:

Prior to getting our new house, we were living with family, so multifamily. We were used to cooking; we had a set schedule assigning days to cook, meals to make, knowing exactly who we're cooking for. We were cooking for not just my husband and myself, but his sister, her family, her Dad, multiple keiki [children] in the house. So at least consciously, we were making sure that we had vegetables in every meal regardless of how big or small.

\section{Aspects of the Community and Phys- ical Environment}

Aspects of the community and the physical environment that facilitate or create barriers towards healthy eating were the second category emerging from the data. Participants identified qualities within their respective communities that made it easy to eat healthy or that created an environment to support healthy eating. As one participant stated, "our community is going into aquaponics [an integrated system to grow fish and plants with the fish waste serving as a food source for the plants, and the plants providing a natural filter for the water the fish thrive in], it's all over my street."

Other participants reflected on the physical environment and the example set by community members:

About this community, we have the space; we have the natural weather to have our own gardens and to be organic. I think that's the best part about this community, we can grow our own vegetables, we can also get fresh meals from the ocean, so we're not fully dependent on the supermarket to supply.

When I see people out in the community exercising, then it makes me think about, I need to change what I'm doing, eat better, exercise more. I think having the open market where more fresh fruits and even different stores that will offer different things. I think that sometimes helps me have access to healthier things.

I'm so happy that our farmers, local people are being acknowledged. Because at a time, we lost some of our water catchment for the $l o ` i$ [taro fields] and things are coming more in the open. I think as a community, we've come further in the past five years than we did for the past 20.

Conversely, attributes within the communities that created barriers to eating healthy were reported:

It takes a lot of strength for me to eat healthy. It's because when I go on the outside, it's so fast food, so it's going to take me to be able to get that salad. Not eat that rice. McDonald's, she's right here, everything is all dollar menu, dollar menu, dollar menu. 
There are not a whole lot of healthy choices out there. I mean, where it's readily available for you, unless you fish. Not even la $a u$ [plant] anymore. I have to go to the neighbor islands so I can gather. Over here, everything is all gone. I don't find that place to be easy anymore.

The cost of living here is one of the biggest drawbacks so even if you wanted to eat healthy, it's not affordable. So we go with what's affordable. It is more costly to be healthy, to eat healthy; the only way would be to just grow your own.

People are trying to survive so they're selling, you got the 'ohana [family] on the road selling laulau [wrapped ti leaf with pork, beef, fish, and/or taro steamed or baked in the ground oven] that is like full of fat. You got the manapua [pork in a bun] trucks all up and down the road. And then just being constantly on the go and having all these fast food establishments everywhere makes it easy to not eat healthy.

Participants also shared their ideas about reducing the barriers in their communities and to eating healthier. Ideas included talking to the plants that they grow to educate merchants or grocers to take the time to plan meals, "The merchants at our area need to be educated on this to help our people. They all gotta be part of this plan."

When you malama [to care], you talk to the plant and it's amazing cause now the kalo is big, we can see little green tomatoes. Today we were cheering cause we see little green tomatoes, but that's how right, you malama that, going malama us. We have more pride in what we going do.

Taking and making the time to plan things out. My husband, he grumbles that foods are too expensive, but I no care, I gotta put something healthy in there, you know, taking the time to, I think that would help and to plan out what they're going to eat and even, the snacks when we go to soccer on Saturdays, being mindful of the kind of snacks that I'm packing. So I want to say the number one thing would be making the time to make the effort to plan better.

Identifying items to sell at the local market co-op demonstrated the value participant's put on community processes which help find the balance between identifying food products to fill a gap and food products of nutritional value. One participant shared a discussion at a co-op meeting:

If we had healthy sandwiches, then that would be an option for you if you didn't have time. Everybody was really into that discussion. Then somebody said, 'we don't have a bakery,' and this girl raises her hand, 'I make malasadas.' And this one lady goes, 'well, what's so healthy about that?' I really think that there's a change coming about.

\section{Deeper Spiritual Meaning of Food}

Participants shared their perceptions of the historical and cultural contexts of food, including significant personal events that served as motivation for life changes. These experiences conveyed a deeper spiritual meaning of food, the third category. As the cosmology of the Hawaiian people describes poi as being significant, not only as a nutritious staple for $\mathrm{Na}$ tive Hawaiians, but as a spiritual food that sustains a population. One participant shared that she wished she had poi, "because it goes good as a staple, and especially because I fed my Mom that, she loves poi."

So the poi we like, I don't know if it's because I'm Hawaiian but my body, my soul just takes to that. I was looking for something that was going to make me full with my eyes and my stomach and I found that through `ulu [breadfruit] and poi [cooked taro, pounded and thinned with water], and through eating sweet potato.

See my Dad, when I was young, he'd have two bowls of poi. One had pink eruption [referring to the fermentation of poi after a few days] and the other one was fresh. He knew I wanted fresh. And all my children, my waiū (milk, breast milk) with fresh poi was their order of the day.

The Wai anae diet was the last time that I actually felt connected to something that I was doing that was beneficial to my body. I felt culturally connected, spiritually connected and it was a real positive experience.

Significant personal events also served as an impetus for change for participants, "bringing up my three grandchildren, when my daughter-in-law left, I had to change the ways of eating."

Three of my classmates died this year from health-related problems. I feel like in my family, I have one grandparent that died early. He was 52. But for some reason, I keep feeling myself aligned with him. My other grandparents, all three of them lived into, well into their late 80's. But I just can't 
seem to connect like I belong to them more than I belong to my grandpa that died early. So I feel scared that something's going to happen to me sooner than later. I didn't get their genes. I got his genes. I don't know this but in my mind, that's what I think.

\section{Ways of Operationalizing Personal Eating Choices}

In the final category, participants described how they operationalized their personal eating choices through the foods they ate or the cues from their body, "the taste of all those flavors together made me feel like I really enjoyed this."

For dinner last night, I had a little rice with a small laulau and that was it. Every day it's different. I don't buy planned meals. I'm against that completely. I try and get fresh vegetable at the open market. I was 'ono [crave] for poi but I wasn't going to catch the bus and go look for poi so I had a little bit of rice.

I was raised with the knowledge, and I'm just naughty. When that one more medication was added, that was like a trigger for me. I said, 'this is it, I just got to stop it.' I guess I needed to be scared or something cause I know. My goodness, I've been in Hawaiian health.

So I've learned to eat like a king in the morning, eat like a queen for lunch, and eat like a slave for dinner. And dinner, I will just skip sometimes because I can't do the fried chicken, or the mushroom gravy, the stew and the roast. I just choose not to do that.

We want to live a pain free life and continue to do what we're doing, continue to eat what we love to eat. It doesn't prevent us from eating that piece of cake or, indulging but it does make us aware of the moderation. You would have your cake and then you would consciously know when to stop and pass it on. So I, and others, depend on the medication and then I think that's what really hurts them and hurts their body and their organs, because of that overeating. So I don't want to be in that situation so I try not to indulge as often.

A lot of my cooking came from my Mom, she influenced me. I try to make something that she loves, chicken long rice, $l \bar{u}$ 'au [taro tops] stew, laulau, butterfish, she loves ake [liver].

\section{Discussion}

People interpret health in diverse and dynamic ways that reflect their personal, historical, social, and cultural experiences, in ways that are far more complex than health outcomes considered by clinicians and scientists. For example, healthy eating has been described in terms of food components and production, physical and psychological outcomes, interrelational and spiritual well-being, environmental impact, and healthy nutrition has been ascribed meanings specific to life stages, life experiences, personal identity, social settings, and community resources. Many dietary practices may be subconscious, rather than intentional.

Participants shed light on Native Hawaiian conceptualization of "healthy nutrition" or "healthy eating" for their family, and in particular for expectant/new mothers and their infants. Key informants were able to provide in-depth information that was culturally grounded about many aspects of personal and community eating patterns. Food choices were associated with past and present family relationships, experiences, and the meaningfulness brought to the participant's life. Participants revealed strong intergenerational influences on current eating patterns which affect the health of their communities.

Today, the intergenerational influences within the 'ohana are operationalized by the person who cooks and determines what and how to prepare the food for their 'ohana. This communal approach can serve as a barrier, as the 'ohana may feel that changes cannot be made out of respect for the person cooking or serve as an opportunity, with the head of the 'ohana (makua or kupuna) taking the lead to make changes, in purchasing or preparing, in growing, and gathering healthy foods. The connection between respect within the family and eating patterns accentuates the importance of community-based approaches to affect meaningful changes in eating patterns among Native Hawaiians.

Many researchers have enumerated individual and community level barriers to healthy eating. We were able to understand in greater depth the barriers and strengths within two specific cultural communities which were both specific to these communities and universal in the participants' goals of creating healthier families. Study participants clearly identified the barriers to eating healthy within their communities, identifying particularly, the abundance of fast food available. The lack of healthy food options in communities with high levels of health disparities has been widely reported in the literature, as food deserts (Slocum \& Saldanha, 2013; Walker, Keane, \& Burke, 2010). Handbury, Rahkovsky, and Schnell (2016) suggest, "access-improving policies alone will eliminate 
less than one-third of existing socioeconomic disparities in nutritional consumption" (para. 1). As participants reported, it is costly to be healthy, affordable to be sick. For individuals, families, and communities to be healthy, planning and resources are required. 'Aina in Hawai i today is unaffordable and the ability to sustain families through growing and gathering healthy foods is inaccessible for most Native Hawaiians. Commitment to stewardship of the 'aina is critical for individuals, families, and communities to feed themselves healthfully, and to ensure that there will be healthy resources available for the next generation. In addition to addressing economic disparities, developing a more in-depth understanding of Native Hawaiians' relationship to the 'aina (that which feeds) is foundational to understanding how healthy eating or healthy nutrition might be facilitated within these communities.

Historical change has and continues to affect the choices Native Hawaiians make about health eating. Traditionally, Native Hawaiians engaged in a cooperative exchange of goods. Those in the uplands made food crops and medicinal plants available, while those on the shoreline provided sea foods and salt. Most of the participants share a common history because of their ages (56-70 years of age), growing up in the 1950s through early 1970s. During this time, the social context for Native Hawaiians and the resources available to them were different than they are today. For example, the Special Supplemental Nutrition Program for Women, Infants and Children, which now creates a nutritional safety net for mothers and children, was not available to participants' families until 1974 when it was permanently authorized by the U.S. government. People's Open Markets in the city and county of Honolulu, whose purpose was to provide the opportunity to purchase agricultural and aquacultural products at low cost, was not founded until 1973. In the 1960s, Native Hawaiians were increasingly concerned about their political rights and cultural identity (Kanahele, 1979). Struggles with land rights came to a pivotal point in Kalama Valley (east O ${ }^{`}$ ahu) in 1970 when non-violent protesters resisted eviction from leased lands in which their homes and farms thrived for more than 20 years (Trask, 2000). This resistance began to spread to other islands, and in 1974 the Native Hawaiian Legal Corporation was formed to address the injustices suffered by Native Hawaiians as a result of being dispossessed from their land. In the early 1970s, cultural traditions began experiencing a strong comeback during a period of time known as the Hawaiian Renaissance (revival of the Hawaiian language, hula, music, canoe voyaging and racing, and craftwork; Kanahele, 1979). These events undoubtedly influenced the availability of resources to families during this period of time.
Efforts in both communities today, to make available healthy produce through farmer's markets, aquaponics, community and individual gardens, and community co-ops may not be fully evident in individual eating patterns for another generation. Thus, our research is inherently temporally grounded with the results reflecting the experiences of community members from a particular period of time, but not those of young families' current experiences. As a result of the historical context displayed in this phase of the study, we developed the second phase of the community assessment in a way that would include younger generations.

\section{Limitations}

The limitations of this study are those inherent in small qualitative studies. No attempt was made to interview a representative sample; rather sampling was purposeful, as appropriate for this type of study. Therefore, this study provides a snapshot of a specific group of people's understandings. Our next phase benefitted from a larger sample size that included voices of males and of younger generations. There is a need for studies of Native Hawaiians in other communities such as urban and neighbor island populations, to further our understanding of eating behaviors.

\section{Implications and Recommendations}

Insight into how a specific cultural group, Native Hawaiians, conceptualizes and operationalizes "healthy eating" or "healthy nutrition" is essential in developing effective initiatives to address obesity-related health inequities currently prevalent in this population. These findings suggest that a person's experiences across generations (what they ate as children, what they were taught, what was available to them, etc.) influence their knowledge of and behavior related to "healthy eating." Participants also shared pivotal experiences that led them to modify their eating behaviors, offering insights into what prompts behavioral change. The CBPR process embraces and provides the opportunity for individuals and their communities to identify the problem and to come up with the solution to resolving this problem. Strategies to successfully address healthy eating in these communities require community ownership and a collective effort to change behavior and the environmental factors that create barriers to "healthy eating."

Our findings provide insights into ways communities, public health providers' program planners, and nurses might better address existing barriers to healthy eating among Native Hawaiian families, ultimately affecting patterns of chronic illness within 
these communities. Nurses are in a pivotal position to assist in changing the trajectory of chronic illness through understanding a cultural group's perception of healthy eating or nutrition. Nursing roles in public health and primary care could assist in initiating appropriate intervention models, particularly with expectant mothers and their families, to affect behavior change. This may impact the prevention of chronic illness. Nurses could also be instrumental in advocating for appropriate cultural and community based interventions with State programs that provide support to expectant mothers to affect population health.

\section{Conclusion}

This study provided meaningful understandings about the nature of Native Hawaiians' perceptions about the relationships between their past history, their current community environments, and their personal struggles that inform and suggest directions for future research and program development. Health inequities for Native Hawaiians will continue to persist unless systemic and generational changes are made at an individual, family, and community level.

\section{Acknowledgments}

The authors wish to extend their sincere gratitude, mahalo nui loa, to the participants and participating communities for their support; the Community Advisory Group and to Puanani Burgess for her skilled consultation.

\section{Declaration of Conflicting Interests}

The authors declared no potential conflicts of interest with respect to the research, authorship, and/or publication of this article.

\section{Funding}

The authors disclose receipt of the following financial support for the research, authorship, and/or publication of this article: This study was supported by the National Institute on Minority Health and Health Disparities [5R24MD008103].

\section{References}

Aluli-Meyer, M. (2015). A'ohe pau ka 'ike I ka hālau ho'okahi: Function, relevance and meaning of Hawaiian epistemology. Paper presented at 'Ike A`o Ho`omana Series of the Native Hawaiian
Center of Excellence, Department of Native Hawaiian Health, John A. Burns School of Medicine, Honolulu, HI.

Bisogni, C. A., Jastran, M., Seligson, M., \& Thompson, A. (2012). How people interpret healthy eating: Contributions of qualitative research. Journal of Nutrition Education and Behavior, 44, 282-301. doi:10.1016/j.jneb.2011.11.009

Elo, S., Kaariainen, M., Kanste, O., Polkki, T., Utriainen, K., \& Kyngas, H. (2014). Qualitative content analysis: A focus on trustworthiness. SAGE Open, 1-10. doi:10.1177/2158244014522633

Handbury, J., Rahkovsky, I., \& Schnell, M. (2016, October). Is the focus on food deserts fruitless? Retail access and food purchases across the socioeconomic spectrum (Working Paper No. 2016-08). Chicago, IL: Becker Friedman Institute for Research in Economics. Retrieved from https://papers.ssrn.com/sol3/papers.cfm?abstract_id=2854329

Handy, E. S. C., \& Pukui, M. K. (1972). The Polynesian family system in Ka`u, Hawai i. Tokyo, Japan: Charles E. Tuttle.

Hawai i State Department of Health. (2011). Hawaii's plan for the prevention of heart disease and stroke 2011-2016. Honolulu, HI: Hawaii State Department of Health, Heart Disease and Stroke Prevention Program. Retrieved from http://health.hawaii.gov/heart-diseasestroke/files/2013/12/HDSP_Plan.pdf

Hawai i State Department of Health. (2012). State of Hawai i primary care needs assessment databook. Retrieved from http://health.hawaii.gov/about/files/2013/06/pcna2012databook.pdf

Hawai i State Department of Health. (2013). Hawai i physical activity and nutrition plan 2013-2020. Retrieved from http://health.hawaii.gov/physical-activity-nutrition/files/2013/08/Hawaii-PAN-Plan2013-2020.pdf

Hawai i State Department of Health, Behavioral Risk Factor Surveillance System. (2016). Coronary heart disease prevalence, for the State of Hawai $i$, for the Year $(s)-2011,2012,2013,2014$. Retrieved from http://hhdw.org/wp-content/uploads/BRFSS_Heart-Disease_IND_00001_20111.pdf

Hawai i State Department of Health, Behavioral Risk Factor Surveillance System. (2016). Diabetes prevalence, for the State of Hawai i, for the Year(s) 2011, 2012, 2013, 2014. Retrieved from http://hhdw.org/wp-content/uploads/BRFSS_Diabetes_IND_00001_2011.pdf

Hawai i State Department of Health, Behavioral Risk Factor Surveillance System. (2015). High blood pressure prevalence, for the State of Hawai $i$, for the year(s) - 2011, 2013. Retrieved from: http://hhdw.org/wp-content/uploads/BRFSS_Hypertension-Blood-Cholesterol_IND_00007_2011.pdf

Hirai, A. H., Hayes, D. K., Taualii, M. M., Singh, G. K., \& Fuddy, L. J. (2013). Excess infant mortality 
among Native Hawaiians: Identifying determinants for preventive action. American Journal of Public Health, 103(11), 88-95. doi:10.2105/ AJPH.2013.301294

Kame`eleihiwa, L. (1992). Native land and foreign desires. Pehea Là E Pono Ai? Honolulu, HI: Bishop Museum.

Kanahele, G. (1979). The Hawaiian renaissance. Honolulu: The Kamehameha Schools Archives. Retrieved from http://kapalama.ksbe.edu/archives/PVSA/ primary\%202/79\%20kanahele/kanahele.htm

Krippendorff, K. (2013). Content analysis: An introduction to its methodology (3rd ed.). Thousand Oaks, CA: SAGE Publications, Inc.

Lipsky, L. M., Haynie, D. L., Liu, D., Chaurasia, A., Gee, B., Li, K., ... Simons-Morton, B. (2015). Trajectories of eating behaviors in a nationally representative cohort of U.S. adolescents during the transition to young adulthood. The International Journal of Behavioral Nutrition and Physical Activity, 12, 138. doi:10.1186/s12966-015-0298-x

Look, M. A., Trask-Batti, M. K., Agres, R., Mau, M. L., \& Kaholokula, J. K. (2013). Assessment and Priorities for Health \& Well-being in Native Hawaiians \& other Pacific Peoples. Honolulu, HI: Center for Native and Pacific Health Disparities Research. Retrieved from http://blog.hawaii.edu/uhmednow/files/2013/09/AP-Hlth-REPORT-2013.pdf

Miller, R. (2007). Using family histories to understand the intergenerational transmission of chronic poverty (Working Paper No. 103). Belfast, Norther Ireland: Chronic Poverty Research Centre. Retrieved from https://papers.ssrn.com/sol3/papers. cfm?abstract_id=1629200

Nguyen, D., \& Salvail, F. R. (2013). The Hawai i Behavioral Risk Factor Surveillance System 2013 results. Honolulu, HI: Hawai i State Department of Health. Retrieved from http://health.hawaii.gov/brfss/files/2014/10/HBRFSS_2013results_OCT06.pdf

Novotny, R., Vijayadeva, V., Grove, J., Gittelsohn, J., Avila, J., Su, Y, \& Murphy, S. (2012). Dietary intake among Native Hawaiian, Filipino, and white children and caregivers in Hawai i. Hawai i Journal of Medicine \& Public Health, 71, 353-358.

Oneha, M. F. M. (2001). Ka mauli o ka āina a he mauli kanaka: An ethnographic study from a Hawaiian sense of place. Pacific Health Dialog, 8, 299-311.

Pobutsky, A., Balabis, J., Nguyen, D-H., \& Tottori, C. (2010). Hawai 'i diabetes report 2010. Honolulu, HI: Hawai'i State Department of Health, Chronic Disease Management and Control Branch, Diabetes Prevention and Control Program. Retrieved from http://www.hawaiihealthmatters.org/javascript/htmleditor/uploads/DOH_DiabetesReport2010_Lo.pdf

Serdula, M. K., Ivery, D., Coates, R. J., Freedman, D. F., Williamson, D. F., \& Byers, T. (1993). Do obesechildren become obese adults? A review of the literature. Preventive Medicine, 22, 167-177. doi:10.1006/pmed.1993.1014

Slocum, R., \& Saldanha, A. (2013). Geographies of race and food: An introduction. In R. Slocum \& A. Saldanha (Eds.), Geographies of race and food: Fields, bodies, markets (pp. 1-23). Burlington, VT: Ashgate.

Thompson, A. L. (2013). Intergenerational impact of maternal obesity and postnatal feeding practices on pediatric obesity. Nutrition Reviews, 71(Suppl. 1), S55-61. doi:10.1111/nure.12054

Thompson-Reid, P. E. (2009). Engaging and mobilizing community members to prevent obesity among adolescents. Preventing Chronic Disease Public Health Research, Practice, and Policy, 6(3), 1-4. Retrieved from http://www.cdc.gov/ pcd/issues/ 2009/jul/pdf/08_0259.pdf

Trask, H. K. (2000). The struggle for Hawaiian sovereignty - Introduction. Problems in paradise: Sovereignty in the Pacific. Retrieved from https://www.culturalsurvival.org/ourpublications/csq/article/thestruggle-for-hawaiian-sovereignty-introduction

U.S. Census Bureau. (2010). American FactFinder. Retrieved from http://factfinder.census.gov/faces/nav/jsf/pages/community_facts.xhtml\#none

U.S. Census Bureau. (2013). 2009-2013 American Coтmunity Survey 5-year estimates Retrieved From https://factfinder.census.gov/faces/tableservices/jsf/pages/productview.xhtml?pid=ACS_14_5 YR_S1101\&prodType $=$ table

U.S. Census Bureau. (2014). 2010-2014 American Coтmunity Survey 5-year estimates. Retrieved from https://factfinder.census.gov/faces/tableservices/jsf/pages/productview.xhtml?pid=ACS_14_5 YR_S1101\&prodType $=$ table

Walker, R. E., Keane, C. R., \& Burke, J. G. (2010). Disparities and access to healthy food in the United States: A review of food deserts literature. Health \& Place, 16, 876-884. doi: 10.1016/j.healthplace.2010.04.013

Wallerstein, N., \& Duran, B. (2008). The theoretical, historical and practice roots of CBPR. In M. Minkler \& N. Wallerstein (Eds.), Community-based participatory research for health: From process to outcomes (2nd ed., pp. 25-46). San Francisco, CA: Jossey-Bass.

Wilson, S. (2001). What is an indigenous research methodology? Canadian Journal of Native Education, 25, 175-179.

Yoon, P.W., Bastian, B., Anderson, R.N., Collins, J.L., \& Jaffe, H.W. (2014, May). Centers for Disease Control and Prevention. Potentially preventable deaths from the five leading causes of death United States, 2008-2010. Morbidity and Mortality Weekly Report, 63(17), 369-374. Retrieved from http://www.cdc.gov/mmwr/pdf/wk/ mm6317.pdf 